\title{
IoT Based Unmanned Toll Booth Monitoring System
}

\author{
Sridevi ${ }^{1}$, Vasantha Pai ${ }^{2}$, Rakesh $\mathbf{Y}^{3}$, Sunil Mendan ${ }^{4}$, Raghavendra Rao $\mathbf{P}^{5}$ \\ Student, ECE, SMVITM, Udupi, India ${ }^{1,2,3,4}$ \\ Asst. Prof., ECE, SMVITM, Udupi, India ${ }^{5}$
}

\begin{abstract}
Managing multiple toll booths is a very complicated task. The system here is a smart card based toll booth system that is monitored using IoT. The Internet server maintains all the data of user accounts and also their balance. All vehicle owners would possess an RFID (Radio Frequency Identification) based card that stores their RFID number. The system at toll booths will monitor the cards scanned when a car arrives at the toll booth. The system then connects to the online server to check if the card is valid and if valid what is the balance. If user balance is sufficient, the toll amount is deducted online and web system sends signal back to the card scanner system that the user has been billed. On receiving this signal the system operates a motor to open the toll gate for that car. The system is controlled by a microcontroller to achieve this purpose. The microcontroller uses Wi-Fi connection to connect to the internet through which system interacts with web server to perform the online verification process. Also system allows to store data of all the vehicles passed at particular time intervals for later reference and surveillance. This system thus automates the entire toll booth billing and monitoring process with ease using RFID plus IoT based system.
\end{abstract}

Keywords: Aurdino, GSM module, RFID, Web server.

\section{INTRODUCTION}

With the growth in the number of vehicles the need for expansive roads catering to thousands of vehicles moving across India has become inevitable. However, considering the present situation the current toll system has several drawbacks. Due to the limited number of toll booths and slow collection process, the average waiting time per vehicle is 10 minutes. This results in losses worth thousands of crores of Rupees in terms of fuel wastage. This long wait time often results in drivers getting irritated resulting in verbal spats and physical fights among people and the toll attendants. Several such incidents have been reported in the press with some of these fights even resulting in the death of the toll plaza attendants. In addition, there are numerous cases of toll plaza accidents which happen due to the sudden lane changing by drivers for faster clearance. The major reason behind this is that, the security at the tolls is insufficient and it is beyond the traffic polices control to manage the vast number of vehicles. We keep hearing of many such incidents at toll plazas which mostly occur due to negligence either on the peoples side or due to lack of control from the government agencies including the police. In case of events, where lives are lost, such losses are a life shattering experience.

As is well known, in such a scenario, the general public is a little hesitant in taking responsibilities of any such incident. Hence the government has to come up with an effective plan which bridges the gap between the toll management and the public expectation of the service that they experience. Introduction of an elective toll plaza operation plan by the government, its strict implementation and monitoring which would result in a more efficient and a more responsive and efficient system could be a good option for easing the challenges associated with the existing tolling process.

The requirements for new web applications supporting different types of devices an purposes are continuously growing. The main advantages of web application development as well as popular development features covering integration with different technologies are considered. Integration and possibilities of application of cloud based web applications in real scenarios with different embedded Internet of Things (IoT) devices are considered and described. The design and implementation of a cloud based web application supporting vehicle toll payment system using IoT device is presented and described. The development framework as well as featured and popular technologies used to realize a vehicle toll payment by IoT device are described. The concept of vehicle toll payment over an online payment system is also described. Processing, monitoring and control in the cloud based web application of such payments using IoT devices are described and presented. Also system allows to store data of all the vehicles passed at particular time intervals for later reference and surveillance. This system thus automates the entire toll booth collection and monitoring process with ease using RFID plus IoT based system. 


\section{International Journal of Innovative Research in} Electrical, Electronics, Instrumentation and Control Engineering

ISO 3297:2007 Certified

Vol. 5, Issue 5, May 2017

\section{METHODOLOGY}

- RFID reader reads the card number and the microcontroller processes the information of the card. Fixed amount is deducted from the user account whenever the valid card scans at the toll booth.

- The online server monitors the data sent by the microcontroller. MySQL database creates the database of the user information which contains the information about the amount remaining and time of entry in the toll.

- A HTML page is used for interaction between user and web.

\section{Block Diagram:}

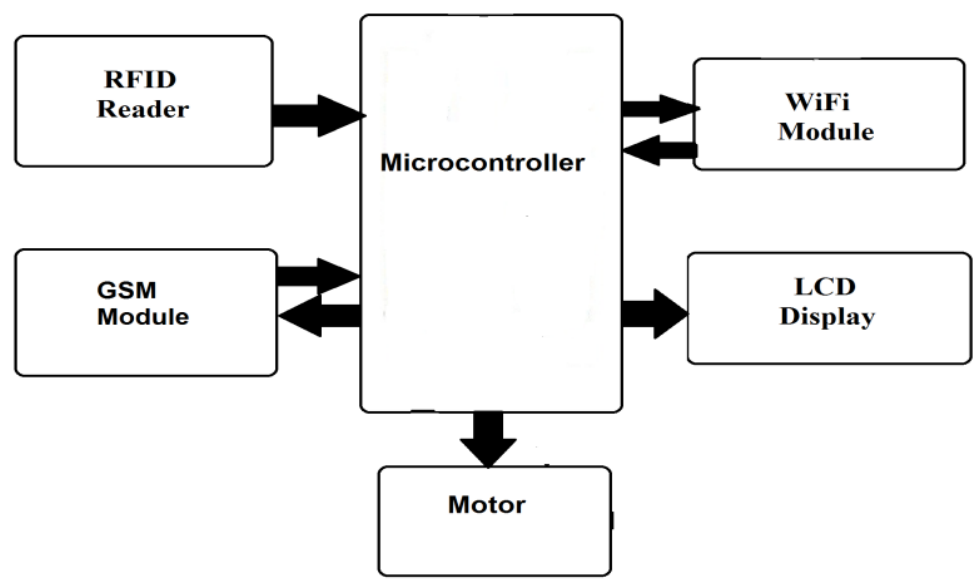

Fig.1.Block diagram of the system

Flow chart:

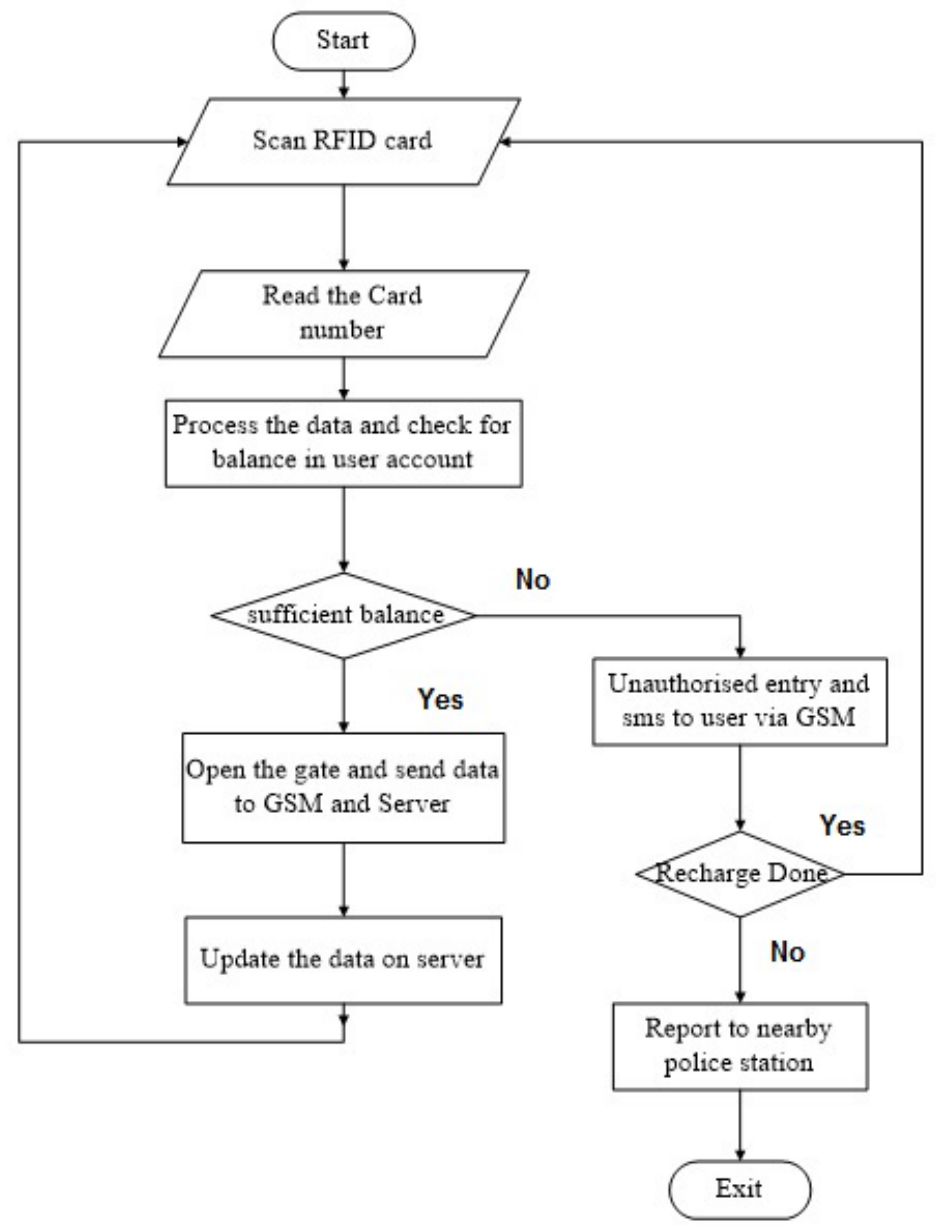


International Journal of Innovative Research in Electrical, Electronics, Instrumentation and Control Engineering

ISO 3297:2007 Certified

Vol. 5, Issue 5, May 2017

Result:

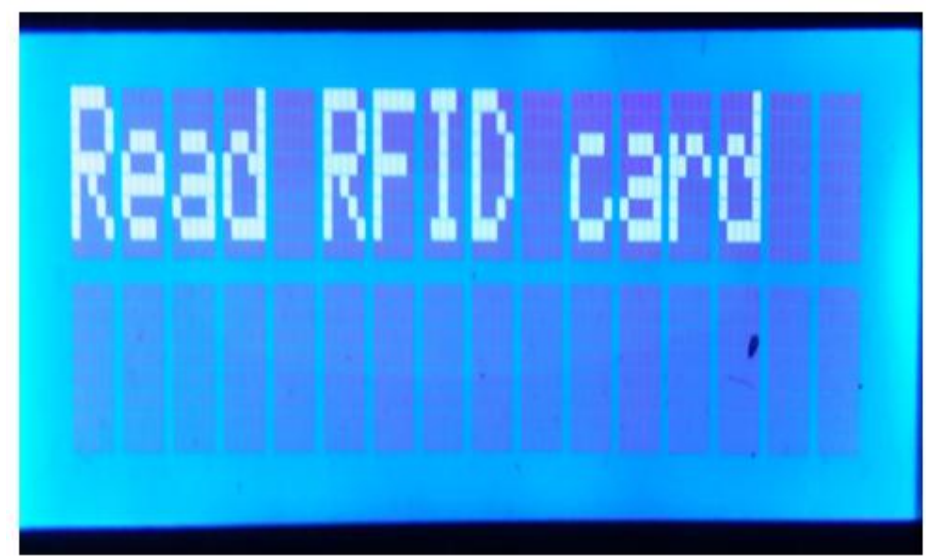

Fig.2. Initial message on LCD

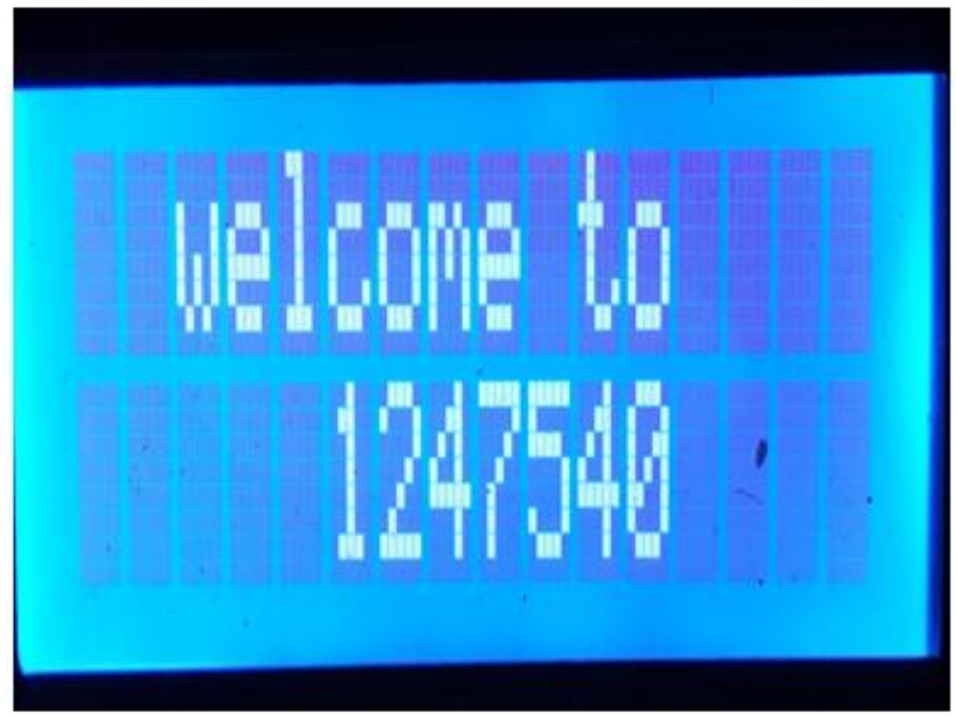

Fig.3. Welcome message

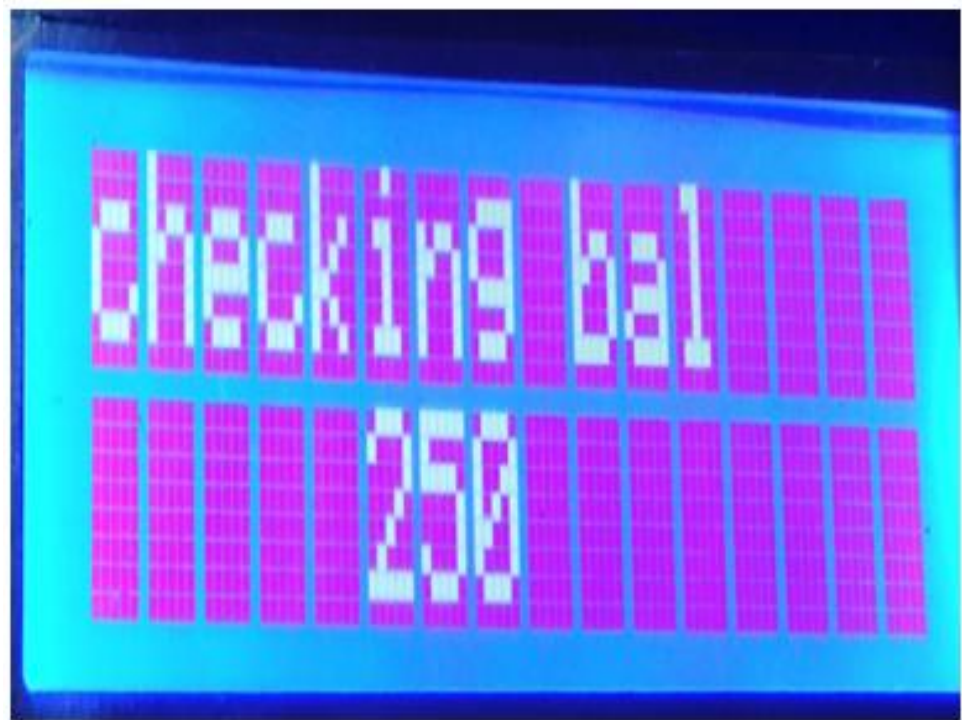

Fig.4.Checks the user balance 


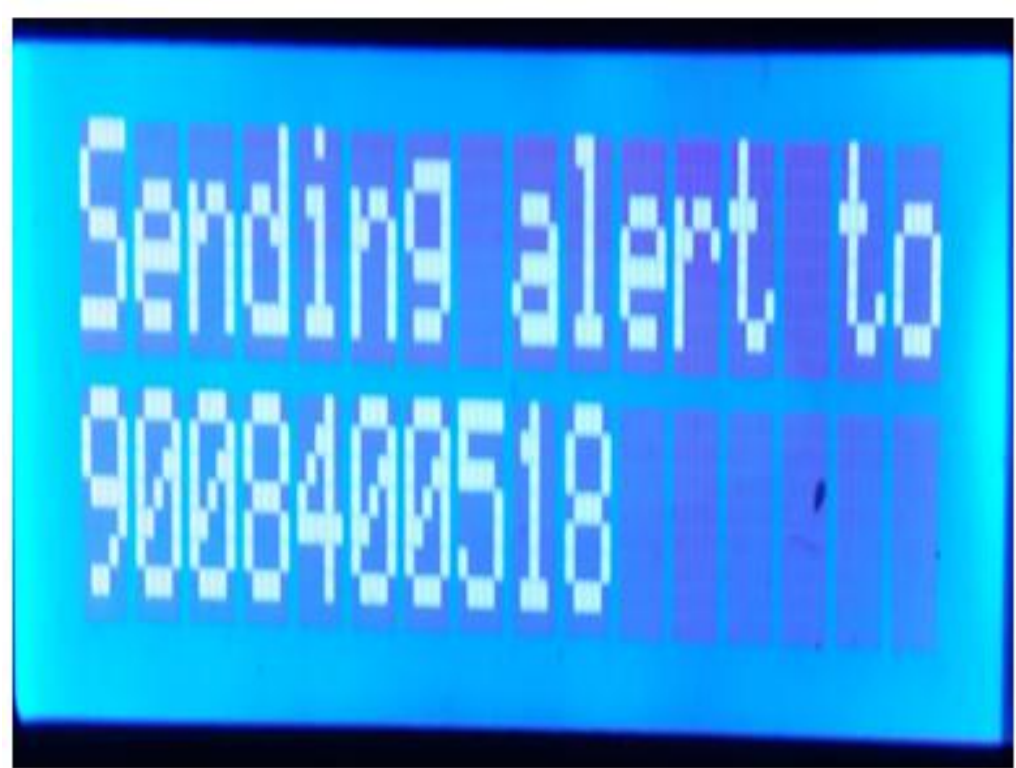

Fig.5.Alerting message

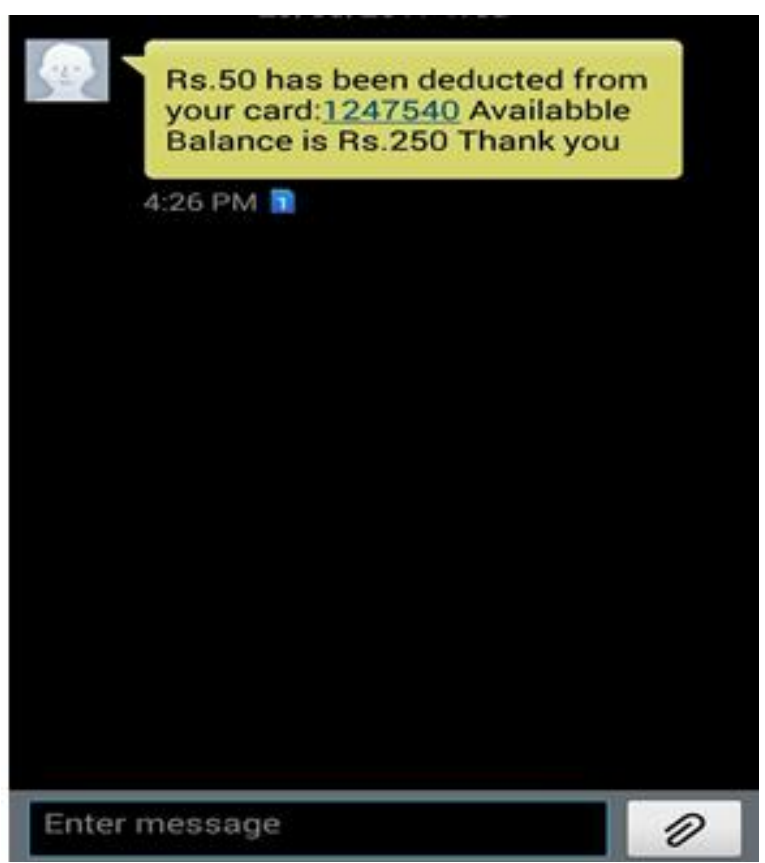

Fig.6. Received message

\section{A. References}

Sighila. $\mathrm{P}$ et al have described a secure RFID gate system that uses IoT technology for better protection. Their system enables the use of internet in connecting di erent devices that are helpful in our day to day life. This type of a gate can be used in large organizations like industries, military or defence area, apartments, etc. Their system also uses Python as it is fast and more e cient. When an unauthorised vehicle approaches the gate, the user needs to inform the person they want to meet so that the person inside can login to the website [1].

Ganesh K. Andurkar\&Vidya R. Ramteke have described a system based on RFID technology. The RFID system used in their system uses a RFID tag and RFID reader which collects information of vehicle passing through the toll plaza and automatically debits the toll amount from prepaid account of vehicle owner, which in return reduces the tra $\mathrm{c}$ congestion and human errors. The vehicle owner has to register his vehicle with provided RFID tag, creating a rechargeable account. When the vehicle will pass through toll gate the amount of toll will automatically be reduced 


\section{IJIREEICE \\ International Journal of Innovative Research in Electrical, Electronics, Instrumentation and Control Engineering \\ ISO 3297:2007 Certified \\ Vol. 5, Issue 5, May 2017}

from user account. They have used microcontroller based system with embedded c coding, and the hardware is interfaced with java based coding [2].

\section{CONCLUSION}

IoT based unmanned toll booth monitoring system is aArduino based toll collection system. The results obtained from working have shown that the system performance is quite reliable. The system has successfully overcome the shortcomings of the ex-isting system by reducing the man power at the toll booth and combining di erent application in same module. It provides easy way of toll collection and maintenance of the information.

\section{REFERENCES}

[1] Sighila. P, VinithaValsan ,Preethibha .C, \IoT Based RFID Gate Automation System", International Journal of Engineering Trends and Technology (IJETT), Vol. 36, Issue 9, June 2016.

[2] Ganesh K. Andurkar, Vidya R. Ramteke, \Smart Highway Electronic Toll Col-lection System", International Journal of Innovative Research in Computer and Communication Engineering (An ISO 3297: 2007 Certied Organization), Vol. 3, Issue 5, May 2015.

[3] Arduino Mega Front view",http://www.electroschematics.com/7963/ arduino-mega-2560-pinout/

[4] RFID Reader",https://communities.intel.com/thread/57844

[5] RFID",https://www.researchgate.net/publication235332138 Development of Java based RFID application programmable interface for heterogeneous RFID system

[6] LCD",https://www.researchgate.net/publication/235332138 Development of Java based RFID application programmable interface for heterogeneous RFID system

[7] GSM SIM900A Module",www.forum.researchdesignlab.com/datasheet/ modules/GSMsim900.pdf

[8] ESP 8266-(ESP 01)",www.sparkfun.com/products/13678

[9] Stepper motor",http://www.instructables.com/id/BYJ48-Stepper-Motor/ 